\title{
Perceptions of Reducing HIV-Preventive Behaviors among Men Who Have Sex with Men Living with HIV in Japan
}

\author{
Yuka Matsutaka1 $^{1}$ Junko Koyano ${ }^{2}$, Yasuharu Hidaka ${ }^{3}$ \\ ${ }^{1}$ Department of Social and Clinical Psychology, Faculty of Contemporary Culture, Hijiyama University, Hiroshima, Japan \\ ${ }^{2}$ Matsuhama Hospital, Niigata, Japan \\ ${ }^{3}$ Takarazuka University School of Nursing, Osaka, Japan \\ Email: matsu-y@hijiyama-u.ac.jp
}

How to cite this paper: Matsutaka, Y., Koyano, J. and Hidaka, Y. (2018) Perceptions of Reducing HIV-Preventive Behaviors among Men Who Have Sex with Men Living with HIV in Japan. Health, 10, 1719-1733.

https://doi.org/10.4236/health.2018.1012130

Received: November 7, 2018

Accepted: December 15, 2018

Published: December 18, 2018

Copyright $\odot 2018$ by authors and Scientific Research Publishing Inc. This work is licensed under the Creative Commons Attribution International License (CC BY 4.0).

http://creativecommons.org/licenses/by/4.0/

\begin{abstract}
Sexual health and behavior among HIV-positive men who have sex with men (MSM) have attracted attention in Japan and elsewhere. It has been reported that perceptions about sex are one factor leading to a reduction in HIV-preventive behaviors. This study investigated types of perceptions, termed self-talk, which allow HIV-positive Japanese MSM to permit themselves to participate in unprotected anal intercourse (UAI). A package of internet surveys for MSM including 20 items assessing self-talk on UAI and condom usage in anal intercourse was administered in 2014. Data from 479 HIV-positive Japanese MSM were analyzed. Exploratory factor analysis was conducted to reveal the factor structure of the self-talk. In addition, using the Kruskal-Wallis test, we examined the relationship between the types of self-talk and the tendency to have UAI. Factor analysis of 20 items assessing self-talk on UAI produced four dimensions: "Diversion/Desire for Stimulation," "Optimism/Defiant Attitude," "Denial of Concern of Transmitting," and "Concern about Relationships." The score of the subscale "Diversion/Desire for Stimulation" was significantly higher than the other three subscales. It was shown that there was a tendency for the self-talk assessed to be associated with the UAI frequency. The types of perceptions permitting UAI and the psychological stress of being an HIV-positive MSM in Japan were discussed. This study was the first to reveal the factorial structure of perceptions in reducing HIV-preventive behaviors among HIV-positive MSM in Japan. We found positive associations between certain types of self-talk and risky sexual behaviors. We provided recommendations for psychosocial support and HIV risk-reduction intervention for HIV-positive MSM.
\end{abstract}




\section{Keywords}

HIV Prevention, Safe Sex, Men Who Have Sex with Men, Perceptions about Sex, Psychological Stress

\section{Introduction}

According to statistics gathered in Japan over the past 30 years, sexual behavior among men who have sex with men (MSM) is a common infection vector for HIV in all age groups of Japanese males. In 2014, 72.3\% of new infections of HIV reported were caused by male sexual contact [1]. There is currently no downward trend in the number of people in Japan living with HIV and AIDS patients. Prevention efforts have not achieved the desired effect. As there are few cases of HIV infection in Japan due to intravenous and vertical transmission, high-risk sexual behaviors among MSM are the most common cause of infection.

In Europe and the United States, the probability of co-infection between HIV and other sexually transmitted diseases (STDs) such as syphilis is very high [2]. In Japan, the same tendency is evident [3] [4] [5]. In addition, previous research shows that the treatment of drug-resistant HIV re-infection caused by sexual intercourse is very difficult [6] [7]. According to a review of research post-2000, the incidence of unprotected anal intercourse (UAI) among HIV-positive MSM was greater than that among uninfected MSM (or who do not know whether they are infected). Thus, it is necessary to raise awareness of safe sex among MSM [8]. With the development of antiretroviral therapy (ART), the strategy of HIV Treatment as Prevention is being advocated and is attracting a great deal of attention [9] [10]. Moreover, the support for sexual health among HIV-positive MSM remains very important.

This study focuses on the sexual behaviors of HIV-positive MSM in Japan, discussing factors affecting safe sex. Whereas there are many risky sexual behaviors, this study focuses on UAI, which easily transmits STDs, as the object of discussion. One approach for the promotion of safe sex among MSM is based on cognitive behavioral theory. Cognitive behavioral theory refers to the idea that individual's behaviors and emotions are influenced by cognitive aspects. In the field of physical and mental health, cognitive behavioral theory is often used to promote individual behavior modifications [11] [12]. According to previous studies, even when male homosexuals know of the risk of infection, many still do not use condoms for anal sex. They may think self-justifying thoughts to allow them to take such an unnecessary risk [13]. For example, if we take a man infected with HIV, who clearly knows the necessity of condom use, such a man, when he has sex with men, may tend to think like this: "I take the antiviral medicine, so having sex without condoms does not matter." We may imagine that eventually he will have unsafe sex. In cognitive behavioral theory, specific thoughts 
that always appear in some given situation are called self-talk (ST) [14]. ST reflects automatic thoughts that cross one's mind unintentionally in various situations and has influence over the behaviors. Therefore, there are compelling reasons to study ST about sex with respect to supporting sexual health.

In this study, to promote the sexual health of MSM living with HIV in Japan, we investigated the contents of their ST in the experience of UAI, and analyzed the relationship between the given ST and the use of condoms for anal sex.

\section{Method}

\subsection{Creating an Inventory of ST}

Matsutaka and colleagues created an inventory of ST (30 items) related to having sex for MSM not infected with HIV (or who did not know whether they are infected) [15]. Based on this inventory, two clinical psychologists, experienced HIV counselors as well as researchers in HIV counseling, produced a draft list (25 items) according to the assessed ST of HIV-positive MSM. We then consulted the opinions of three experienced HIV counselors and six HIV-positive MSM to ensure the draft was reasonable, and modified it according to their suggestions. Eventually, we had a list of 20 items, called the Self-talk inventory of UAI experience for HIV-positive MSM (P-UAIST) (Appendix).

\subsection{Participants and Procedure}

We added P-UAIST to "REACH Online 2014," a package of internet surveys for MSM. This package of internet surveys included several self-report questionnaires to be filled out anonymously published on a website. The website was protected by Secure Socket Layer (SSL) encryption.

We advertised the survey through banner advertisements on websites for gay men and in applications for smart phones. Information on the surveys was also published on social networking services such as Mixi and Twitter. Potential participants were directed to a website to learn more about the survey. In the first section of the site, we presented informed consent information introducing the aims and methods of the study in detail, in order to ensure consent was obtained. If participants understood the purposes of the study and agreed to the terms of participation, they clicked an "Agree" button, and they then accessed the questionnaires.

In order to ease access to the users of a variety of information technology tools, the answer system for the questionnaires was constructed so as to be used by personal computers, smart phones, tablet computers, and mobile phones. Data were collected between August 28 and December 15, 2014. The study protocol was approved by the Ethics Committee of Takarazuka University School of Nursing.

Exclusion criteria for participation were the following: 1) unique character string assigned to browser cookie matched a previous one (the answers may be from the same computer terminal); 2) participant selected a nonbiological male 
gender; 3) participant reported an overseas residence; 4) the content of an answer was obviously wrong, for example if the age chosen has more than 3 digits; and 5) participant did not react to specific word tracers.

Demographic data included age, residence, educational background, annual income, and sexual orientation. Participants were also asked about their history of sexually transmitted diseases, HIV treatment, sexual behavior, medications, and mental health. These issues are also included in "REACH Online 2014." However, in this paper, we discussed only issues related to P-UAIST. There were 20,821 valid responses to "REACH Online 2014." In this study, we chose participants who had a history of HIV infection and also had UAI within the past 6 months, as target data for analysis. In total data from 497 participants who completed the P-UAIST were used. We did not calculate sample size before sampling.

Participants were told to recall their experience of UAI while responding to the P-UAIST. Each item in P-UAIST was rated on a 5-point Likert scale ranging from 1 (not at all) to 5 (extremely).

\subsection{Data Analysis}

Statistical analysis was conducted using SPSS v.23. First, descriptive statistics were examined for the demographic data and all items of P-UAIST. Second, exploratory factor analysis was conducted to reveal the factor structure of P-UAIST. Finally, using the Kruskal-Wallis test, we examined whether there were significant differences among frequency of condom use for those who had anal sex in the past 6 months (options included "very often," "almost half of the time," "rarely," and "never").

\section{Results}

\subsection{Demographic Data}

Demographic characteristics $(\mathrm{N}=497)$ are presented in Table 1. Almost all respondents were homosexual or bisexual. Most were 30 to 40 years old. With regard to frequency of condom use among those who had anal sex in the past 6 months, $61.4 \%$ of respondents answered "rarely" and "never."

\subsection{Answer Tendencies and Factor Structure of P-UAIST}

The answer tendencies of P-UAIST are presented in Table 2. The percentage of "somewhat" and "extremely" was high for the following items: "item 11: I want to enjoy having sex without thinking" (65.4\%), "item 7: I want strong stimulation, and barebacking is more stimulating" (61.0\%), and "item 8: I can't feel much pleasure unless I have sex bareback" (57.3\%).

In order to examine the factor structure, we conducted an exploratory factor analysis using principal factor analysis and applying an oblique rotation (Pro$\max )$ on the items of P-UAIST, extracting four factors according to the eigenvalue and the rationality of the content. This result is shown in Table 3. The first 
Table 1. Demographic data $(\mathrm{N}=497)$.

$\mathrm{n}(\%)$

[Age (Average age 36.7, $\mathrm{SD}=7.3$ )]

$$
\begin{gathered}
10-19 \\
20-29 \\
30-39 \\
40-49 \\
50-
\end{gathered}
$$

[Sexual orientation]

$$
\begin{gathered}
\text { Homosexual } \\
\text { bisexual } \\
\text { heterosexual } \\
\text { I do not know } \\
\text { I cannot decide } \\
\text { No answer }
\end{gathered}
$$

[Frequency of use of condoms when having anal sex (in the past 6 months)]

$$
\begin{gathered}
\text { Always } \\
\text { Sometimes } \\
\text { Rarely } \\
\text { Never }
\end{gathered}
$$

[Sex partner male (in the past 6 months) ${ }^{\mathrm{a}}$ ]

A lover or other specific partner Yes

Friends or other sexual partners Yes

$$
\text { No }
$$

One night stand Yes

$409(82.6)$

No

$86(17.4)$

[Hospital attendance situation (HIV treatment)]

Do an outpatient visit

Used to do an outpatient visit

Stopped going to the hospital

$15(3.0)$

[Medication (anti HIV drugs)]

Taking medicine

Used to take medicine

\begin{tabular}{|c|c|c|c|c|c|c|c|c|c|c|}
\hline \multirow[b]{3}{*}{ Items } & \multirow{2}{*}{\multicolumn{2}{|c|}{$\begin{array}{c}1 . \\
\text { not at all }\end{array}$}} & \multirow{2}{*}{\multicolumn{2}{|c|}{$\begin{array}{l}2 . \\
\text { not realy }\end{array}$}} & \multirow{2}{*}{\multicolumn{2}{|c|}{$\begin{array}{c}3 . \\
\text { undecided }\end{array}$}} & \multirow{2}{*}{\multicolumn{2}{|c|}{$\begin{array}{c}4 . \\
\text { somewhat }\end{array}$}} & \multicolumn{2}{|c|}{$(\mathrm{N}=497)$} \\
\hline & & & & & & & & & ext & mely \\
\hline & $\mathrm{n}$ & $(\%)$ & $\mathrm{n}$ & $(\%)$ & $\mathrm{n}$ & $(\%)$ & $\mathrm{n}$ & $(\%)$ & $\mathrm{n}$ & $(\%)$ \\
\hline $\begin{array}{l}\text { 1. The number of viruses is very small, they should not be } \\
\text { transmitted to others. }\end{array}$ & 127 & $(25.6)$ & 57 & (11.5) & 124 & $(24.9)$ & 143 & $(28.8)$ & 46 & $(9.3)$ \\
\hline
\end{tabular}

Not taking medicine

[Recent viral load]

Below threshold

$$
\begin{gathered}
\text { Above 100,000 } \\
\text { Unchecked }
\end{gathered}
$$

$22(4.4)$

No answer

Note: axcluded two non-responses.

Table 2. Illustration of modal choices for items of P-UAIST. 


\section{Continued}

2. If the partner wants to have unsafe sex, it would be his

3. The partner might have been infected with HIV, but using condoms is unnecessary.

4. I am BOTTOM ${ }^{\mathrm{a}}$, and the chance that my partner will be infected is very small.

5. This man probably makes love with many people bareback, so he will not know who he is infected by.

6. Even if the partner was infected, he could still live normally by undergoing treatment. It would not be a big deal.

7. I want strong stimulation, and barebacking is more stimulating.

8. I can't feel much pleasure unless I have sex bereback

9. Just for today, barebacking is not a big deal.

10. It could make us feel happier to have sex bareback.

11. I want to enjoy having sex without thinking.

12. May be it was strange to use condoms now because we have not used them for a while.

13. If we never do internal cumshot, having sex bareback is not a problem.

14. If I could have sex with this guy, I would not care about using condoms.

15. I may be alienated from my partner if I refused to have sex bareback.

16. If I propose that we use condoms, people would suspect that I am carrying HIV. being co infected by other sexually transmitted diseases.

18. I am taking the antiviral medicine, so I will not be re-infected with HIV.

19. This guy does not look like he is carrying HIV, so it is unnecessary to use condoms.

20. I am TOP ${ }^{b}$, so even if I do not use condoms, the chance to be HIV or STD infected will still be very small. responsibility if it got transmitted.

17. Anyway, I have been infected with HIV, I do not care about

\begin{tabular}{|c|c|c|c|c|c|c|c|c|c|}
\hline 49 & (9.9) & 48 & (9.7) & 158 & (31.8) & 146 & (29.4) & 96 & (19.3) \\
\hline 129 & $(26.0)$ & 57 & (11.5) & 152 & $(30.6)$ & 107 & (21.5) & 52 & (10.5) \\
\hline 189 & $(38.0)$ & 74 & (14.9) & 133 & (26.8) & 85 & $(17.1)$ & 16 & $(3.2)$ \\
\hline 97 & (19.5) & 60 & (12.1) & 155 & $(31.2)$ & 115 & $(23.1)$ & 70 & (14.1) \\
\hline 164 & $(33.0)$ & 74 & (14.9) & 169 & $(34.0)$ & 59 & (11.9) & 31 & $(6.2)$ \\
\hline 79 & (15.9) & 28 & $(5.6)$ & 87 & (17.5) & 134 & $(27.0)$ & 169 & $(34.0)$ \\
\hline 75 & (15.1) & 47 & (9.5) & 90 & (18.1) & 119 & (23.9) & 166 & (33.4) \\
\hline 116 & (23.3) & 51 & (10.3) & 141 & (28.4) & 112 & (22.5) & 77 & (15.5) \\
\hline 172 & $(34.6)$ & 43 & (8.7) & 141 & (28.4) & 70 & (14.1) & 71 & (14.3) \\
\hline 62 & (12.5) & 33 & (6.6) & 77 & (15.5) & 150 & $(30.2)$ & 175 & (35.2) \\
\hline 120 & $(24.1)$ & 41 & $(8.2)$ & 128 & (25.8) & 121 & $(24.3)$ & 87 & (17.5) \\
\hline 191 & $(38.4)$ & 63 & (12.7) & 126 & (25.4) & 76 & (15.3) & 41 & $(8.2)$ \\
\hline 107 & (21.5) & 49 & (9.9) & 105 & $(21.1)$ & 107 & $(21.5)$ & 129 & $(26.0)$ \\
\hline 165 & $(33.2)$ & 72 & $(14.5)$ & 127 & $(25.6)$ & 82 & (16.5) & 51 & (10.3) \\
\hline 183 & $(36.8)$ & 64 & (12.9) & 118 & (23.7) & 75 & $(15.1)$ & 57 & (11.5) \\
\hline 252 & (50.7) & 70 & (14.1) & 91 & (18.3) & 45 & $(9.1)$ & 39 & (7.8) \\
\hline 255 & (51.3) & 79 & (15.9) & 99 & (19.9) & 37 & $(7.4)$ & 27 & (5.4) \\
\hline 223 & (44.9) & 70 & (14.1) & 120 & $(24.1)$ & 55 & (11.1) & 29 & (5.8) \\
\hline 309 & $(62.2)$ & 61 & (12.3) & 85 & (17.1) & 29 & $(5.8)$ & 13 & $(2.6)$ \\
\hline
\end{tabular}

Note: ${ }^{a}$ TOP means the one who puts his penis in another man's anal. 'BOTTOM means the one who prefers to the recipient when having sex.

Table 3. Results of factor analysis (principal factor analysis, Promax).

\begin{tabular}{|c|c|c|c|c|c|c|}
\hline & & 1) & 2) & 3) & 4) & Communality \\
\hline \multicolumn{7}{|c|}{ [The first factor: Diversion/Desire for Stimulation $(\alpha=0.87)$ ] } \\
\hline 7 & $\begin{array}{l}\text { I want strong stimulation, and barebacking is more } \\
\text { stimulating. }\end{array}$ & 0.94 & -0.03 & 0.00 & -0.13 & 0.75 \\
\hline 8 & $\begin{array}{l}\text { I can't feel much pleasure unless I have sex } \\
\text { bereback. }\end{array}$ & 0.87 & 0.08 & -0.09 & -0.19 & 0.62 \\
\hline 11 & I want to enjoy having sex without thinking. & 0.75 & -0.12 & 0.13 & -0.03 & 0.57 \\
\hline 10 & It could make us feel happier to have sex bareback. & 0.61 & 0.01 & 0.00 & 0.21 & 0.55 \\
\hline
\end{tabular}




\section{Continued}

\begin{tabular}{|c|c|c|c|c|c|c|}
\hline 14 & $\begin{array}{l}\text { If I could have sex with this guy, I would not care } \\
\text { about using condoms. }\end{array}$ & 0.50 & -0.04 & 0.07 & 0.26 & 0.48 \\
\hline 9 & Just for today, barebacking is not a big deal. & 0.44 & 0.21 & 0.00 & 0.14 & 0.46 \\
\hline \multicolumn{7}{|c|}{ [The second factor: Optimism/Defiant Attitude $(\alpha=0.79)]$} \\
\hline 18 & $\begin{array}{l}\text { I am taking the antiviral medicine, so I will not be } \\
\text { re-infected with HIV. }\end{array}$ & -0.03 & 0.76 & 0.09 & -0.15 & 0.48 \\
\hline & I am TOP, so even if I do not use condoms, the & & & & & \\
\hline 20 & $\begin{array}{l}\text { chance to be HIV or STD infected will still be very } \\
\text { small. }\end{array}$ & -0.08 & 0.65 & -0.06 & 0.10 & 0.42 \\
\hline 19 & $\begin{array}{l}\text { This guy does not look like he is carrying HIV, so it } \\
\text { is unnecessary to use condoms. }\end{array}$ & 0.04 & 0.64 & -0.14 & 0.22 & 0.60 \\
\hline 13 & $\begin{array}{l}\text { If we never do internal cumshot, having sex } \\
\text { bareback is not a problem. }\end{array}$ & 0.07 & 0.62 & -0.10 & 0.04 & 0.41 \\
\hline 4 & $\begin{array}{l}\text { I am BOTTOM, and the chance that my partner } \\
\text { will be infected is very small. }\end{array}$ & -0.07 & 0.49 & 0.12 & -0.01 & 0.27 \\
\hline 1 & $\begin{array}{l}\text { The number of viruses is very small, they should } \\
\text { not be transmitted to others. }\end{array}$ & 0.01 & 0.47 & 0.03 & -0.10 & 0.19 \\
\hline 17 & $\begin{array}{l}\text { Anyway, I have been infected with HIV, I do not } \\
\text { care about being co infected by other sexually } \\
\text { transmitted diseases. }\end{array}$ & 0.07 & 0.37 & 0.13 & 0.04 & 0.28 \\
\hline \multicolumn{7}{|c|}{ [The third factor: Denial of Concern of Transmitting $(\alpha=0.79)$ ] } \\
\hline 5 & $\begin{array}{l}\text { This man probably makes love with many people } \\
\text { bareback, so he will not know who he is infected by. }\end{array}$ & -0.08 & -0.09 & 0.87 & 0.10 & 0.67 \\
\hline 3 & $\begin{array}{l}\text { The partner might have been infected with HIV, so } \\
\text { using condoms is unnecessary. }\end{array}$ & 0.06 & 0.10 & 0.72 & -0.11 & 0.59 \\
\hline 2 & $\begin{array}{l}\text { If the partner wants to have unsafe sex, it would be } \\
\text { his responsibility if it got transmitted. }\end{array}$ & 0.12 & -0.06 & 0.53 & -0.07 & 0.31 \\
\hline 6 & $\begin{array}{l}\text { Even if the partner was infected, he could still live } \\
\text { normally by undergoing treatment. It would not be } \\
\text { a big deal. }\end{array}$ & 0.00 & 0.28 & 0.51 & 0.03 & 0.51 \\
\hline \multicolumn{7}{|c|}{ [The fourth factor: Concern about Relationships $(\alpha=0.72)$ ] } \\
\hline 15 & $\begin{array}{l}\text { I may be alienated from my partner if I refused to } \\
\text { have sex bareback. }\end{array}$ & -0.08 & -0.03 & -0.01 & 0.80 & 0.56 \\
\hline 16 & $\begin{array}{l}\text { If I propose that we use condoms, people would } \\
\text { suspect that I am carrying HIV. }\end{array}$ & -0.07 & 0.02 & -0.03 & 0.79 & 0.57 \\
\hline 12 & $\begin{array}{l}\text { Maybe it was strange to use condoms now because } \\
\text { we have not used them for a while. }\end{array}$ & 0.20 & 0.04 & 0.15 & 0.39 & 0.41 \\
\hline & Inter-factor correlations 1) & - & 0.57 & 0.61 & 0.50 & \\
\hline & 2) & - & - & 0.53 & 0.69 & \\
\hline & 3) & - & - & - & 0.40 & \\
\hline
\end{tabular}

factor was "Diversion/Desire for Stimulation," which included six items, such as "I want to enjoy having sex without thinking." The second factor was "Optimism/Defiant Attitude," which included seven items such as "I am taking the antiviral medicine, so I will not be re-infected with HIV." The third factor was "Denial of Concern of Transmitting," which included four items, such as "This 
man probably makes love with many people bareback, so he will not know who he is infected by." The fourth factor was "Concern about Relationships," which included three items such as "I may be alienated from my partner if I refused to have sex bareback." All factors showed adequate internal consistency ( $\alpha=0.72$ $0.87)$.

The mean level of each factor was provided as the subscale score. The mean level of "Diversion/Desire for Stimulation" was 3.27 (SD =1.10), the mean level of "Optimism/Defiant Attitude" was 2.23 (SD =0.84), the mean level of "Denial of Concern of Transmitting" was 2.90 ( $\mathrm{SD}=0.99$ ), and the mean level of "Concern about Relationships" was 2.70 (SD = 1.12). One-way ANOVA (repeated measures) yielded significant differences among these subscale scores (F (2.74, $1361.01)=176.18, \mathrm{p}<0.01)$, and post hoc comparisons revealed that there were significant differences between all subscale scores $(\mathrm{p}<0.01)$. Pearson product-moment correlation coefficients are shown in Table 4.

\subsection{Relationship between the Types of ST and the Tendency to Have UAI}

To examine the relationship between the types of ST and the tendency to have UAI, a Kruskal-Wallis test was conducted, with the frequency of condom use in anal sex within the past 6 months and the subscales of P-UAIST. Nonparametric procedures were used, because the variances for each group were not even. The analysis revealed a significant difference in all subscales of P-UAIST among frequency of condom use (Table 5). Multiple comparison tests were conducted.

The scores in "Diversion/Desire for Stimulation" of those who chose for condom use the responses "almost half of the time" $(p<0.01)$, "rarely" $(p<0.001)$, and "never" ( $p<0.001)$ were significantly higher than those who chose "very often." The scores of those who chose "rarely" $(p<0.01)$ and "never" $(p<0.001)$ were significantly higher than the scores of those who chose "almost half of the time." In the "Optimism/Defiant Attitude" subscale, the scores of those who chose "rarely" ( $p<0.01)$, and "never" ( $p<0.01)$ were significantly higher than the scores of those who chose "very often." For "Denial of Concern of Transmitting," the score of those who chose "rarely" ( $p<0.01)$ and "never" $(p<0.01)$ were significantly higher than the scores of those who chose "very often." The scores of those who chose "rarely" were significantly higher than the scores of those who chose "almost half of the time" $(p<0.05)$. In the "Concern about

Table 4. Correlation coefficients of P-UAIST.

\begin{tabular}{ccccc}
\hline & 1 & 2 & 3 & 4 \\
\hline 1. Diversion/Desire for Stimulation & - & $0.53^{\star * *}$ & $0.57^{\star * *}$ & $0.48^{\star * *}$ \\
2. Optimism/Defiant Attitude & - & - & $0.49^{\star * *}$ & $0.57^{\star * *}$ \\
3. Denial of Concern to Transmitting & - & - & - & $0.38^{\star * *}$ \\
4. Concern about Relationships & - & - & - & -
\end{tabular}

${ }^{* * *} \mathrm{p}<0.001$ 
Table 5. Condom usage and subscales of P-UAIST.

\begin{tabular}{lcc}
\hline & Mean rank & $\chi^{2}$ \\
\hline Diversion/Desire for Stimulation & & \\
Very often & 138.97 & $74.39^{* * *}$ \\
Almost half of the time & 213.03 & \\
Rarely & 279.54 & \\
Never & 298.67 & $12.76^{* *}$ \\
Optimism/Defiant Attitude & & \\
Very often & 196.01 & \\
Almost half of the time & 244.7 & \\
Rarely & 264.29 & \\
Never & 261.74 & \\
Denial of Concern of Transmitting & & \\
Very often & 193.61 & \\
Almost half of the time & 226.74 \\
Rarely & 272.69 \\
Never & $268.69^{* * *}$ \\
Concern about Relationships & 258.02 & \\
Very often & & \\
Almost half of the time & & \\
Rarely & 256.83 & \\
Never & & \\
\hline
\end{tabular}

${ }^{* * *} \mathrm{p}<0.001,{ }^{* *} \mathrm{p}<0.01,{ }^{*} \mathrm{p}<0.05$

Relationships" subscale, the scores of those who chose "rarely" were significantly higher than the scores of those who chose "very often" ( $\mathrm{p}<0.05)$.

\section{Discussion}

In this study, we investigated types of ST that MSM use to permit a risky sexual behavior (UAI) to themselves, and the relationship between the types of ST and tendency for UAI among HIV-positive MSM in Japan.

We consider that these results stem from samples that are comparatively high risk for transmission of HIV and other STDs, because the targets of analysis are limited to men who had UAI with other men, and $61.4 \%$ of them responded "never" or "rarely" to whether they used a condom when they had anal intercourse in the previous six months.

Exploratory factor analysis of the P-UAIST reveals four factors: "Diversion/Desire for Stimulation," "Optimism/Defiant Attitude," "Denial of Concern of Transmitting," and "Concern about Relationships." These factors correlate each other. Kruskal-Wallis test reveals a significant difference in all subscales of P-UAIST among frequency of condom use. Thus, we can state that the tendency 
of occurrence of these types of ST is associated with the rate of UAI.

The score for the subscale "Diversion/Desire for Stimulation" is significantly higher than the other three subscales, and is strongly associated with the frequency of UAI. These results demonstrate that this type of ST plays an important role in UAI among HIV-positive MSM in Japan. As previous studies have suggested that many MSM or gay/bisexual men have experienced psychological stress and mental-health problems because of stigma with regard to their sexuality [16] [17] [18], this type of ST implies that the desire to be free from psychological stress forms the background to unprotected sex. HIV-positive MSM face multiple forms of stigma and discrimination due to both their sexual identity and their HIV status; that is, they suffer from dual stigma [19]. Therefore, policy makers should consider the specific needs of this population when designing HIV prevention, care, and treatment services.

Among HIV-positive MSM, one motivation for substance use is to increase sexual pleasure [20]. Substance use is associated with risky sexual behaviors including UAI [21]. A previous study suggested that Japanese MSM with depressive symptoms may use substances to cope, and it also showed that being diagnosed as HIV-positive is a risk factor for lifetime multiple substance use, while UAI is associated with both lifetime single and lifetime multiple substance use [22]. Sexual health support programs for MSM should focus on both reducing substance use and on reducing psychological stress.

The nature of the types of ST "Optimism/Defiant Attitude" and "Denial of Concern of Transmitting" is involved with the underestimation or denial of the possibility of transmitting HIV to the sexual partner or becoming infected with other STDs, including drug resistant HIV. Improvements in HIV/AIDS treatment and its accessibility have brought great benefits to people living with HIV. On the other hand, this situation has resulted in an optimistic view of transmission risk among MSM. Some previous studies suggested that such an optimistic view was a factor in sexual risk behaviors in MSM [23] [24]. We consider that these two types of ST reflect the optimistic view. In addition, according to the type of ST "Denial of Concern of Transmitting," HIV-positive MSM often care about their responsibility to perform HIV-prevention behaviors, but the issue may become clouded in their mind, and then they may have UAI. In particular, it is likely that the thought of responsibility tends to fade easily in an anonymous or one-night sex venue. It is notable that more than half $(61.4 \%)$ of analysis targets had one-night stands with men. Although the motivation to protect oneself from infection by a drug-resistant strain of HIV or by other STDs may be a solution for optimism or denial of responsibilities, self-esteem is necessary to protect oneself, and it was suggested that the level of self-esteem of Japanese MSM is low [25]. There is a need for a psychosocial approach to encourage or maintain MSM self-esteem in sexual health support interventions.

The type of ST "Concern about Relationships" reflects anxiety about the mood of sex partners or concern over being suspected of serostatus by sex partners if 
UAI is refused. It is suggested that HIV-related stigma was correlated with loneliness, and loneliness was negatively associated with condom usage [26]. HIV-positive MSM may not refuse UAI because of loneliness, which can be brought about by stigma.

Previous research in Western countries examining the nature of thoughts with regard to UAI suggested that HIV-positive MSM focused on themes regarding the deferral of responsibility, the assumption that the partner is positive, or that sex without a condom fulfills emotional needs [27]. Our results targeting Japanese HIV-positive MSM are generally similar to Western research, apart from the aspect of "Concern about Relationships," which reflects anxiety about the mood of the sex partner or being suspected serostatus by the sex partner and may be unique among HIV-positive Japanese MSM.

Taken together, this study strongly suggests that the psychosocial approach, including work with psychological stress, self-esteem, and loneliness, as well as social or internalized stigma, is warranted to encourage safer sex of MSM.

Several limitations require consideration concerning this study. First, our results stem from samples aged mostly from 20 to 50, and reflect few characteristics of other developmental stages, such as those of adolescence or old age. Second, as this was an online survey, the participants were limited to only those MSM that use the internet, and is also limited to MSM who use those sites where the advertisement was placed and to those MSM who are likely to click on advertisements on such sites. Thus, our findings may not be generalizable to MSM. Finally, this study does not examine perceptions about UAI in relation to differences in serostatus or with regard to the sex venue.

Future research should examine how to put different types of ST to practical use to create effective programs to encourage safer sex for HIV-positive MSM. Several studies in other countries have examined strategies to reduce risky sexual behaviors for HIV-positive MSM by focusing on perceptions or beliefs about sex and transmission risk [28] [29]. In Japan, a study examined personalized cognitive behavioral counseling-an original program for Japanese HIV-negative MSM for HIV prevention, focusing on ST, and showed its effectiveness in reducing risky sexual behaviors [30]. However, no research thus far has examined programs for HIV prevention focusing on ST for Japanese HIV-positive MSM. A good use of our findings for HIV-positive MSM would be to use them to build programs to encourage safer sex.

\section{Conclusion}

This study is the first to reveal the factorial structure of perceptions, or ST, in reducing HIV-preventive behaviors among HIV-positive MSM in Japan. In addition, associations between the ST and UAI are discussed. It is strongly suggested that a psychosocial approach, including work centering on psychological stress and social or internalized stigma, is warranted to encourage safer sex among MSM. 


\section{Acknowledgements}

This research was supported by a Grant-in-Aid for AIDS Research from the Ministry of Health, Labor, and Welfare of Japan in 2014.

\section{Conflicts of Interest}

The authors declare no conflicts of interest regarding the publication of this paper.

\section{References}

[1] HIV/AIDS Surveillance Committee (Japan) (2014) Annual Report of the HIV/AIDS Surveillance 2014. http://api-net.jfap.or.jp/status/2014/14nenpo/h26gaiyo.pdf

[2] Centers for Disease Control and Prevention, Division of STD Prevention (2015) Sexually Transmitted Disease Surveillance 2014.

http://www.cdc.gov/std/stats14/surv-2014-print.pdf

[3] Koike, K., Kikuchi, Y., Kato, M., Takamatsu, J., Shintani, Y., Tsutsumi, T., Fujie, H., Miyoshi, H., Moriya, K. and Yotsuyanagi, H. (2008) Prevalence of Hepatitis B Virus Infection in Japanese Patients with HIV. Hepatology Research, 38, 310-314. https://doi.org/10.1111/j.1872-034X.2007.00263.x

[4] Yamashita, M., Fujii, Y., Ozaki, K., Urano, Y., Iwasa, M., Nakamura, S., Fujii, S., Abe, M., Sato, Y. and Yoshino, T. (2015) Human Immunodeficiency Virus-Positive Secondary Syphilis Mimicking Cutaneous T-Cell Lymphoma. Diagnostic Pathology, 10, 185. https://doi.org/10.1186/s13000-015-0419-5

[5] Kojima, Y., Kawahata, T., Mori, H., Furubayashi, K., Taniguchi, Y., Iwasa, A., Taniguchi, K., Kimura, H. and Komano, J. (2013) Prevalence and Epidemiological Traits of HIV Infections in Populations with High-Risk Behaviors as Revealed by Genetic Analysis of HBV. Epidemiology \& Infection, 141, 2410-2417. https://doi.org/10.1017/S0950268812003123

[6] Hattori, J., Shiino, T., Gatanaga, H., Yoshida, S., Watanabe, D., Minami, R., Sadamasu, K., Kondo, M., Mori, H., Ueda, M., Tateyama, M., Ueda, A., Kato, S., Ito, T., Oie, M., Takata, N., Hayashida, T., Nagashima, M., Matsuda, M., Ibe, S. Ota, Y., Sasaki, S., Ishigatsubo, Y., Tanabe, Y., Koga, I., Kojima, Y., Yamamoto, M., Fujita, J., Yokomaku, Y., Koike, T., Shirasaka, T., Oka, S. and Sugiura, W. (2010) Trends in Transmitted Drug-Resistant HIV-1 and Demographic Characteristics of Newly Diagnosed Patients: Nationwide Surveillance from 2003 to 2008 in Japan. Antiviral Research, 8, 72-79. https://doi.org/10.1016/j.antiviral.2010.07.008

[7] Truong, H-H.M., Kellogg, T.A., McFarland, W., Louie, B., Klausner, J.D., Philip, S.S. and Grant, R.M. (2011) Sentinel Surveillance of HIV-1 Transmitted Drug Resistance, Acute Infection and Recent Infection. PLoS ONE, 6, e25281. https://doi.org/10.1371/journal.pone.0025281

[8] Nicole, K.M.C., Harm, H.J. and Gerjo, K. (2007) Sexual Risk Behavior among HIV-Positive Men Who Have Sex with Men: A Literature Review. Patient Education and Counseling, 65, 5-20. https://doi.org/10.1016/j.pec.2006.09.003

[9] Scott, M. and Hammer, M.D. (2011) Antiretroviral Treatment as Prevention. New England Journal of Medicine, 365, 561-562. https://doi.org/10.1056/NEJMe1107487

[10] Cohen, M.S., Chen, Y.Q., McCauley, M., Gamble, T., Hosseinipour, M.C., Kumarasamy, N., Hakim, J.G., Kumwenda, J., Grinsztejn, B., Pilotto, J.H., Godbole, S.V., Mehendale, S., Chariyalertsak, S., Santos, B.R., Mayer, K.H., Hoffman, I.F., Eshle- 
man, S.H., Piwowar-Manning, E., Wang, L., Makhema, J., Mills, L.A., de Bruyn, G., Sanne, I., Eron, J., Gallant, J., Havlir, D., Swindells, S., Ribaudo, H., Elharrar, V., Burns, D., Taha, T.E., Nielsen-Saines, K., Celentano, D., Essex, M. and Fleming, T.R. (2011) Prevention of HIV-1 Infection with Early Antiretroviral Therapy. New England Journal of Medicine, 365, 493-505. https://doi.org/10.1056/NEJMoa1105243

[11] Niall, M., Tara, C., Grainne, O. and Emma, S. (2014) Motivational Strategies for Physiotherapists. Physical Therapy Reviews, 19, 136-142. https://doi.org/10.1179/1743288X13Y.0000000117

[12] Matthew, C.R., Catherine, W.E., Bennedict, W. and Glen, B.W. (2009) Aggression Replacement Training in Australia: Youth Justice Pilot Study. Psychiatry, Psychology and Law, 16, 413-426. https://doi.org/10.1080/13218710902852859

[13] Gold, R.S. (2004) Explaining Gay Men's Unrealistic Optimism about Becoming Infected with HIV. International Journal of STD \& AIDS, 15, 99-102. https://doi.org/10.1258/095646204322764280

[14] Gold, R.S. (2000) AIDS Education for Gay Men: Towards a More Cognitive Approach. AIDS Care, 12, 267-272. https://doi.org/10.1080/09540120050042909

[15] Matsutaka, Y., Koyano, J., Kuwano, M., Hashimoto, M., Honma, T., Yamazaki, H., Yokoyama, Y. and Hidaka, Y. (2013) An Examination about Perceptions in Reducing HIV-Preventive Behaviors among Men Who Have Sex with Men. The Journal of AIDS Research, 15, 134-140.

[16] King, M., Semlyen, J., Tai, S.S., Killaspy, H., Osborn, D., Popelyuk, D. and Nazareth, I. (2008) A Systematic Review of Mental Disorder, Suicide, and Deliberate Self Harm in Lesbian, Gay and Bisexual People. BMC Psychiatry, 8, 70. https://doi.org/10.1186/1471-244X-8-70

[17] Berlan, E.D., Corliss, H.L., Field, A.E., Goodman, E. and Austin, S.B. (2010) Sexual Orientation and Bullying among Adolescents in the Growing up Today Study. Journal of Adolescent Health, 46, 366-371. https://doi.org/10.1016/j.jadohealth.2009.10.015

[18] Halkitis, P.N. (2012) Reframing HIV Prevention for Gay Men in the United States. American Psychologist, 65, 752-763. https://doi.org/10.1037/0003-066X.65.8.752

[19] Kennedy, C.E., Baral, S.D., Fielding-Miller, R., Adams, D., Dludlu, P., Sithole, B., Fonner, V.A., Mnisi, Z. and Kerrigan, D. (2013) "They Are Human Beings, They Are Swazi": Intersecting Stigmas and the Positive Health, Dignity and Prevention Needs of HIV-Positive Men Who Have Sex with Men in Swaziland. Journal of the International AIDS Society, 16, 187491.

[20] Semple, S.J., Strathdee, S.A., Zians, J. and Patterson, T.L. (2009) Sexual Risk Behavior Associated with Co-Administration of Methamphetamine and Other Drugs in a Sample of HIV-Positive Men Who Have Sex with Men. The American Journal of Addictions, 18, 65-72. https://doi.org/10.1080/10550490802544466

[21] Purcell, D.W., Parsons, J.T., Halkitis, P.N., Mizuno, Y. and Woods, W.J. (2001) Substance Use and Sexual Transmission Risk Behavior of HIV-Positive Men Who Have Sex with Men. Journal of Substance Abuse, 13, 185-200. https://doi.org/10.1016/S0899-3289(01)00072-4

[22] Hidaka, Y., Ichikawa, S., Koyano, J., Urao, M., Yasuo, T., Kimura, H., Ono-Kihara, M. and Kihara, M. (2006) Substance Use and Sexual Behaviors of Japanese Men Who Have Sex with Men: A Nationwide Internet Survey Conducted in Japan. BMC Public Health, 6, 239. https://doi.org/10.1186/1471-2458-6-239

[23] Brennan, D.J., Welles, S.L., Miner, M.H., Ross, M.W. and Rosser, B.R.S. (2010) HIV 
Treatment Optimism and Unsafe Anal Intercourse among HIV-Positive Men Who Have Sex with Men: Findings from the Positive Connections Study. AIDS Education and Prevention, 22, 126-137. https://doi.org/10.1521/aeap.2010.22.2.126

[24] Peterson, J.L., Miner, M.H., Brennan, D.J. and Rosser, B.R.S. (2012) HIV Treatment Optimism and Sexual Risk Behaviors among HIV Positive African American Men Who Have Sex with Men. AIDS Education and Prevention, 24, 91-101. https://doi.org/10.1521/aeap.2012.24.2.91

[25] Hidaka, Y. and Operario, D. (2009) Hard-to-Reach Populations and Stigmatized Topics: Internet-Based Mental Health Research for Japanese Men Who Are Gay, Bisexual, or Questioning Their Sexual Orientation. In: Sher, L. and Vilens, A., Eds., Internet and Suicide, Nova Science Publications Inc., New York, 319-332.

[26] Hubach, R.D., Dodge, B., Li, M.J., Schick, V., Herbenick, D., Ramos, W.D., Cola, T. and Reece, M. (2015) Loneliness, HIV-Related Stigma, and Condom Use among a Predominantly Rural Sample of HIV-Positive Men Who Have Sex with Men (MSM). AIDS Education and Prevention, 27, 72-83.

https://doi.org/10.1521/aeap.2015.27.1.72

[27] Skinta, M.D., Murphy, J.L., Paul, J.P., Schwarcz, S.K. and Dilley, J.W. (2012) Thoughts, Attitudes, and Feelings of HIV-Positive MSM Associated with High Transmission-Risk Sex. Health Education \& Behavior, 39, 315-323. https://doi.org/10.1177/1090198111427390

[28] Josepha, H.A., Flores, S.A., Parsons, J.T. and Purcell, D.W. (2010) Beliefs about Transmission Risk and Vulnerability, Treatment Adherence, and Sexual Risk Behavior among a Sample of HIV-Positive Men Who Have Sex with Men. AIDS Care, 2, 29-39. https://doi.org/10.1080/09540120903012627

[29] Schwarcz, S.K., Chen, Y.H., Murphy, J.L., Paul, J.P., Skinta, M.D., Scheer, S., Vittinghoff, E. and Dilley, J.W. (2013) A Randomized Control Trial of Personalized Cognitive Counseling to Reduce Sexual Risk among HIV-Infected Men Who Have Sex with Men. AIDS Care, 25, 1-10. https://doi.org/10.1080/09540121.2012.674095

[30] Koyano, J., Matsutaka, Y., Kuwano, M., Hayatsu, M., Nishikawa, A., Hoshino, S., Gotou, D., Machi, T. and Hidaka, Y. (2014) Trial for HIV Prevention Intervention That Reaches "the Moment" Examination of Personalized Cognitive Behavioral Counseling for MSM. The Journal of AIDS Research, 16, 92-100. 


\section{Appendix: Items of Self-Talk Inventory of UAI Experience for HIV-Positive MSM (P-UAIST)}

1. The number of viruses is very small, they should not be transmitted to others.

2. If the partner wants to have unsafe sex, it would be his responsibility if it got transmitted.

3. The partner might have been infected with HIV, but using condoms is unnecessary.

4. I am BOTTOM ${ }^{\mathrm{a}}$, and the chance that my partner will be infected is very small.

5 This man probably makes love with many people bareback, so he will not know who he is infected by.

6. Even if the partner was infected, he could still live normally by undergoing treatment. It would not be a big deal.

7. I want strong stimulation, and barebacking is more stimulating.

8. I can't feel much pleasure unless I have sex bereback.

9. Just for today, barebacking is not a big deal.

10. It could make us feel happier to have sex bareback.

11. I want to enjoy having sex without thinking.

12. May be it was strange to use condoms now because we have not used them for a while.

13. If we never do internal cumshot, having sex bareback is not a problem.

14. If I could have sex with this guy, I would not care about using condoms.

15. I may be alienated from my partner if I refused to have sex bareback.

16. If I propose that we use condoms, people would suspect that I am carrying HIV.

17. Anyway, I have been infected with HIV, I do not care about being co infected by other sexually transmitted diseases.

18. I am taking the antiviral medicine, so I will not be re-infected with HIV.

19. This guy does not look like he is carrying HIV, so it is unnecessary to use condoms.

20. I am TOP ${ }^{\mathrm{b}}$, so even if I do not use condoms, the chance to be HIV or STD infected will still be very small.

Note: aTOP means the one who puts his penis in another man's anal; ${ }^{\mathrm{B}} \mathrm{BOTTOM}$ means the one who prefers to the recipient when having sex. 